\title{
Influence of Taxes in the Mobilization of Financial Resources
}

\author{
Djaxongir R. Zaynalov" and Zarif O. Ahrorov* \\ \#Samarkand Institute of Economics and Service, Samarkand, Uzbekistan
}

Received 01 April 2019, Accepted 04 June 2019, Available online 06 June 2019, Vol.9, No.3 (May/June 2019)

\begin{abstract}
The article is devoted to the study of the relationship between the inflation process, the state budget, tax exemptions from household incomes, as well as the stimulation of investment activity of corporations. In order to assess the interrelationship of these financial and economic phenomena, the opinions of various domestic foreign scientists and government officials were reviewed, and practical data from a number of countries that took place in different time periods were analyzed. The effect of the considered indicators on income and investment activity of the population and corporations is shown. The authors' opinion is given in relation to the policies pursued by different countries in this area.
\end{abstract}

Keywords: Tax, taxation, inflation, inflation process, economic crisis, tax burden, financial resources, budget.

\section{Introduction}

The modern international financial and economic crisis is characterized by the extreme aggravation of all contradictions that occur in market relations. This crisis periodically shakes the economy, the discrepancy between production growth and effective demand is constantly deepening. Prices are constantly rising, inflation is the number one problem. Expanded reproduction in these conditions becomes impossible without the active intervention of the state, which in the interests of the economy with the help of finance redistributes a significant part of the national income.

Mobilization of financial resources is carried out mainly by tax methods. Taxes, providing the state with the possibility of diverse political, economic and social activities, are also used by the state as an anti-crisis, anti-inflationary tool.

Hence there is a need to analyze the interconnection of such important economic categories as taxes and inflation. This problem is not new, in its time it was the subject of discussion in the domestic economic literature. However, the changes that have taken place in society could not but affect these categories. Currently, the relationship between them has been modified and acquired new moments. The importance of their consideration is due to the fact that taxes and inflation serve as a means of regulating the activities of enterprises. The correctness of their assessment is of great importance in the struggle to prevent the negative effects of the crisis.

*Corresponding author Zarif $\mathbf{0}$. Ahrorov is an Independent Researcher (ORCID ID: 0000-0003-4403-9137); Djaxongir R. Zaynalov is working as Professor

DOI: https://doi.org/10.14741/ijcet/v.9.3.16

\section{Literature Review}

Traditionally, taxes and inflation were thought to be inversely related. Such an assessment was based on the fact that taxes and the issue of money, the consequence of which was largely inflation, act as the main types of state budget revenue. A review of the Uzbek economic literature (Sh. Toshmatov, 2008, B. Toshmurodova 2002, T. Malikov, 2007, 0. Olimjonov, 1999, A. Juraev, 2004, H. Kurbonov, E.Gadoev, 2005)revealed that in the scientific works, there is a perception that, given the relative sustainability of the budget, the growth of one of these indicators will inevitably entail a reduction of the other, and vice versa. In addition, an increase in taxes, as noted by us in previously published works (Zaynalov D.R., 2010, Ahrorov Z.O. 2018), leads to a reduction in the population's effective demand for goods and services, since the income of the population intended for purchase is collected by the state as a means of easing the inflation process.

This interpretation of the dependence of taxes and inflation is somewhat simplified, but, to a certain extent, it actually reflected and still reflects the development of the financial system. In fairness it should be noted that the size of budgets, taxes and budget deficits in relation to national income before the first stage of transition to the market were relatively small. The state resorted to issuing paper money only in the years of financial difficulties, when tax revenues did not provide increased spending Inflation was episodic and hit only individual countries. 


\section{Findings and Results}

The era of the financial and economic crisis is characterized by a huge increase in tax revenues (Fig.1).

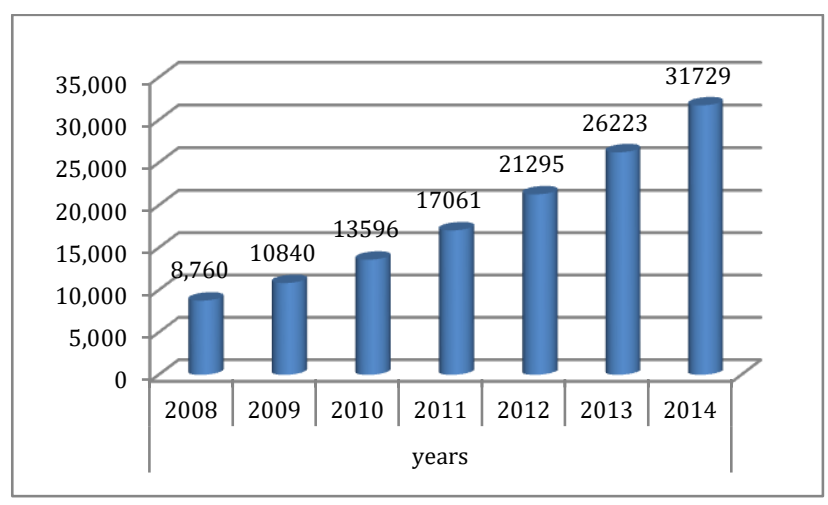

Fig.1. Increase in tax revenue Source: Ministry of Finance of the Republic of Uzbekistan

Taxes began to perform along with the fiscal function and the function of state intervention in the production process. In the context of this, we noted that the inflation process, which expresses a violation of the process of production and money circulation, is closely connected with government regulation (Zaynalov D.R., 2015). The integral features of inflation are globality, chronic character, and increasing rates (Fig.2).

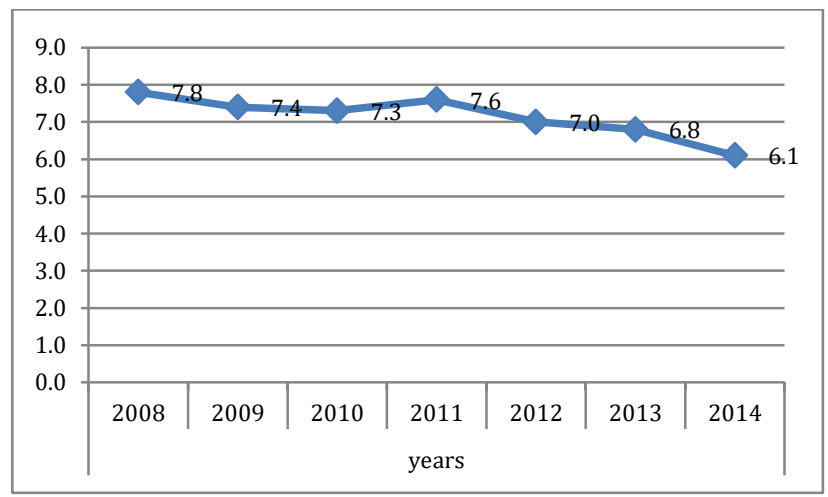

Fig.2. Inflation rate changes

Source: Data of the State Statistics Committee of the Republic of Uzbekistan

Modern taxes and inflation, as before, are the various methods of redistributing national income in the interests of big capital at the expense of the masses. Taxes are enforced predominantly on workers mobilizing an increasing share of national income.

So, in 2008 the share of all taxes (state and local) and social security contributions in the UK national income amounted to about 30\%, and in $2012-40 \%$. These funds are used to preserve and strengthen the general conditions of production, to enrich enterprising entrepreneurs. Inflation through rising commodity prices creates conditions for deepening inequality in society. The lag in growth of nominal wages from price increases contributes to the accumulation of wealth in the financial oligarchy.

The scale of this tax and inflation redistribution of national income increases as its volume increases. Taxes and inflation reinforce the property stratification of society and isolate a small group of monopolistic subject. So, according to economists, currently 75-80\% of the national wealth of developed countries is owned by only $5-7 \%$ of the population.

Accelerating the redistribution of national income, both economic categories affect each other. On the one hand, taxes, by increasing commodity prices, increase the inflation process, and on the other hand, the tax burden increases under the influence of inflation.

In connection with the growth of defense spending and the expansion of state intervention in production, costs are constantly increasing, to cover which more and more tax revenues are required. The main types of taxes are corporate income taxes, social insurance contributions and various indirect taxes. In the republican budget for fiscal year 2011, for example, they amounted to 11.0 trillion soums, which covered 99.7\% of all expenses. Taxes have a constant upward trend. Over the past ten years, revenues from them have increased by almost 2.5 times.

Profit tax, social insurance contributions and indirect taxes of all kinds have a direct impact on the prices of goods and services and deepen the inflation process. Thus, the tax on the profits of enterprises in a certain part is passed on to the consumer. One of the main methods of translation is its inclusion in the price of goods and services sold. The current social system of entrepreneurs and hired workers, in the case of additional taxation, always compensates for itself with lower wages and higher prices.

In modern conditions, a significant increase in profits and a slight increase in tax rates leads to an absolute increase in tax revenues to the budget. In the UK, for example, the corporate tax rate increased from $40 \%$ in 1966 up to $52 \%$ in 1977 The revenues from this tax in the state budget for fiscal years 1966/1967$1977 / 1978$ increased almost 2.5 times, although their share in total tax revenues decreased from 11.9 to 9.2\% (Report of the Commissioners of Her Majesty's Inland Revenue, 1978).

With the growth of corporate income tax, the scale of the arrangement also increases. According to American economists, the company paid about half of the taxes paid on profits through the price of goods sold. The practice of including tax in the price of goods in modern conditions has become so widespread that even the economic press does not hide this fact. The American economist P. Sarris wrote: "Entrepreneurs, paying increased taxes, have less profits and, in order to prevent this, they raise prices" (S.P. Sarris, 1970). Contributions to the social insurance fund are paid by the insured and entrepreneurs. In the foreign press, contributions are considered as production costs reimbursed by buyers in the price of goods. The size of these contributions is continuously increasing, which 
leads, among other reasons, to higher prices. In the US, these contributions increased from 1\% in 1937 up to $5.85 \%$ of the payroll in 1978 . This reached $7.15 \%$ (U.S. News and World Report, 1978).

Indirect taxes are by nature taxes to the consumer who pays them in the price of goods and services. In developed countries, almost all personal consumption goods bear indirect taxes. French economists S. Brie and P. Sharpantier wrote that "... in the family's shopping bag there are over 300 different taxes." A large tax coverage of goods occurred as a result of the introduction of a universal excise (turnover tax), in which the object of taxation is not an individual commodity, but the value of the turnover of the enterprise's goods. Currently, a special type of tax is widely used - value added tax levied on the value added at each stage of production and distribution.

For indirect taxes, others are also characterized by a continuous increase in rates, and, above all, valueadded tax rates. So, in Germany the basic rate of this tax was established in January 1968 in the amount of $10 \%$, and from January 1977 it is increased to $13 \%$. And in the future it is expected to bring it to $15 \%$ (Dandelablait, 1976). Such an increase in tax rates inevitably causes a rise in prices for consumer goods by at least $1.5-2.5 \%$. So, taxes and, above all, income tax, social insurance contributions, indirect taxes, increasing commodity prices, together with other factors, increase the inflation process and reduce the real purchasing power of the population.

Population inflation, accompanied by the depreciation of paper money, has a different impact on taxpayers. Under the influence of inflation, there is a reduction in taxation and an increase in the tax burden. Taxes on individuals with high incomes as a result of various benefits provided by the state in connection with the growth of commodity prices are constantly decreasing. Deferral of payments, systematic revaluation of fixed capital, tax rebates at a rapid rate of depreciation of money are turned into additional income for entrepreneurs.

The real value of the tax amount with increasing security of money decreases. The greater the gap between the moment of tax accrual and the moment of its payment in case of high inflation, the more the taxpayer benefits. The income of individuals and enterprises is paid on a tax return. For example, in the United States, the filing of declarations and the payment of corporate income tax is made quarterly, although the owner receives his income much more often. In addition, the US government allows entrepreneurs to have a tax arrears of $20 \%$ of the amount due. In the event that this amount is higher, the corporation pays a penalty of $6 \%$ per annum. This procedure provides owners with significant benefits. A particularly large gap between the receipt of income and the payment of tax arises under preferential taxation. Usually, pre-emptive taxes are levied 1-2 times a year, whereas the owner receives the income of land and house on a monthly, quarterly basis.
Consequently, any deferment of payment with a strong depreciation of money turns into an additional profit for the owner, since the tax salary in real terms is reduced. At the same time, workers and employees pay income tax at the time of earning income, so they do not have any benefits.

In terms of inflation, some owners receive special tax breaks from the state. In the process of circulation capital periodically takes different forms (monetary, productive, commodity). With the rapid growth of prices, certain parts of capital (raw materials, machinery, labor) acquired by an entrepreneur at different times are valued in money of various purchasing power. Therefore, the real cost of production costs deviates up and down from their maximum expression. Meanwhile, entrepreneurs believe that the difference in the monetary valuation of capital overstates the financial results and leads to a re-taxation of their income (Curwen P., 1976). This is the basis for the requirement of workers new tax breaks.

In France, where inflation rates are particularly strong, the government provides for a revaluation of capital, and profits at a certain ratio in order to free it from taxation on that part of the profit, which is regarded as purely nominal. Even this is provided for in the budget itself, i.e. revaluation of company assets. It is important to take the company out of bankruptcy.

The policy of accelerated depreciation, due to scientific and technological progress, provides rapid accumulation of funds for the reimbursement of fixed capital. The depreciation fund increases due to the continuous increase in prices for equipment and machinery. In the interests of the company, the state increases depreciation rates and permits to write off tax-free profits in amounts that substantially exceed the actual amount of depreciation of fixed assets. Essentially, accelerated depreciation stimulated by high inflation rates means tax subsidies for new investments.

In addition to accelerated depreciation, governments of market-developed countries to stimulate capital accumulation provide investment discounts that are not deductible on taxable income, like most tax discounts, but directly on the assessed amount of tax. In the USA, this exemption is valid at a rate of $10 \%$ of the expenditure on the purchase of equipment and machinery, and in 1977 an additional discount of $4 \%$ of the contribution of entrepreneurs to the social insurance fund or $2 \%$ of the cost of new capital investments was established (U.S.News and World Report, 1977).

For workers, inflation means a deterioration in their financial situation, since the real wages of workers and the salaries of employees are reduced as a result of rising prices. However, inflation does not affect the livelihoods of the population through prices, it also increases the tax burden. It should be recognized. So, in our opinion, one of the worst effects of inflation is to force everyone to pay higher taxes. The 
impact of inflation on the taxation of workers can go in several directions: the progressiveness of taxation increases, although it does not significantly provide for its reduction, which has the character of progressiveness. Taxes on individuals in the context of inflation is changing: it increases for the population and weakens for monopoly infrastructures.

With rising prices for goods, there is a decrease in the real incomes of workers, which causes an aggravation of the social situation of the population.

As a result of inflationary growth in cash income, even with the relative stability of progressive tax rates on individuals, the burden of taxation automatically increases. A taxpayer with a higher nominal income moves in the group with higher tax rates. As a consequence, the tax rate or the proportion of income subject to taxation increases. In our opinion, even if the middle-class family income grows due to inflation, its purchasing power may suffer due to an increase in progressive tax rates on individuals and an increase in social insurance contributions. According to our calculations, the purchasing power for this group of the population can be up to $3-4 \%$.

The progressive scale of tax rates on individuals is structured in such a way that for low and medium incomes the intervals of the groupings are narrower than for high ones, and their changes are more significant. So, in the mid-60s, progressive taxation of household incomes was practiced and is still in effect. For example, in the USA, the rate for small incomes is increased by 1 point for every $\$ 500$ in revenue. Revenues from $\$ 500$ to 10 thousand dollars. taxed at rates that range from 14 to $36 \%$ (scale for singles). Therefore, even a small nominal increase in cash income for low incomes led to an increase in taxation. The particular burden of income tax was felt by large families. The average American family paid in the form of income tax contributions to the social insurance fund and local taxes 11.8 of their earnings, and in 1975 $22.7 \%$. In general, the progressiveness of income tax for the population with the fall in the purchasing value of money increased (Significant Features of Fiscal Federalism, 1977).

Even today, progression is different for employers. The income tax scale has great advantages for a payer with high incomes: the intervals of groupings are significant and the rates grow slowly, the progression ends at a certain level of income. Frequent cases of reducing the maximum rate, as well as income to which it applies. In the USA, for example, the maximum rate is up to 1964 reached $94 \%$, and in 1976 reduced to $70 \%$. Even during the US presidency of D. Carter (19781979), reduce it to $68 \%$. In English tax practice, a decrease in income is observed, to which the maximum rate is applied: in 1929/30, the fiscal year is 50 thousand pounds. Art. 1938 / 39-30 thousand, 1978/79 financial year-23 thousand f.st.

Even if the rate scale remains unchanged for many years, the taxation of large incomes with a sharp increase in profits from inflation loses its progressive nature. With the growth of income, the payer rises on the scale and reaches the maximum ceiling, and from that moment on the income tax becomes proportional. Therefore, in general, the effectiveness of progress is reduced.

High and maximum income tax rates are rarely used on taxation. The main reason is tax evasion. There was a kind of "tax freedom" for the rich. Recipients of large and largest incomes pay insignificant taxes or do not pay them at all. In the US, about 300 rich people with incomes of more than 200 thousand dollars. each in 1970 evaded paying taxes (Economic Notes, 1972). As shown by a study made in 1976. Commission of the US Congress, the 17 largest corporations have not paid a single dollar tax (Bulletin of foreign commercial information, 1978).

American economist F. Lundberg wrote, Nearly all of the revenue, moreover 86 per cent of it comes from the lower brackets, from the initial rate that all must pay. Differently put, the less than 1 per cent of the individuals who own upward of 70 per cent of productive property throw only 14 per cent into the tax caldron as their distinctive, differentiated contribution, while their own publications metronomically salute them as pillars of society (Lundberg F., 1969).

Providing money leads, among other reasons, to an increase in the number of income tax payers, mainly due to low-paid workers. This is explained by the fact that with the growth of nominal incomes, the nontaxable minimum and personal discounts remain unchanged or increase very slowly. Therefore, lowincome individuals, previously free of income tax, are now becoming its payers. In the USA, for example, for the period 1967-1975. the exemption minimum for singles has increased from $\$ 600$ to $\$ 750$, i.e. by $25 \%$. During the same time, the price index increased by $57 \%$; essentially the real value of the non-taxable minimum was halved. As a result, the number of payers of federal income tax increased during 1950-1974 by 151\% (Statistical Abstract of the U.S., 1976). The same applies to family, personal discounts on income tax and their increase significantly lags behind the increase in the cost of living. In the UK, the income level from which the family begins to pay has also sharply increased. Currently, an English family becomes an income tax payer when its income is much lower than the official poverty level. This situation is observed in other market-developed countries.

English economist Chris Pond provides a comparative analysis of tax deductions for families with two children over ten years. The conclusion is as follows. In the 1975/76 fiscal year, the family of a worker with two children paid $10 \%$ of her income to the state, whereas ten years ago she did not pay income tax at all under the same conditions. If you take into account social security contributions, the share of tax increases even more. For families with average earnings, the tax increases significantly (by 260\%), whereas for families with high incomes, its growth was only 60\% (Lewis P., 1975). 
So, the growth of nominal income with a constant increase in commodity prices causes an increase in the tax burden, and in general, inflation exacerbates the inequality of taxation. In the English press provides data on the distribution of income tax, depending on the size of income by year. The analysis shows that the share of income tax paid by the richest English families is steadily decreasing (Hansard, 1975). For five years (1967-1972), the share of income tax per $1 \%$ of families with high incomes in the total amount of income decreased by 5.5 points (from 20.5 to $15 \%$ ). The share fell even more for $10 \%$ of rich families (by 8 points), while for the poorest income groups the tax burden increased by $27 \%$.

In connection with the acceleration of the rate of inflation and the growth of tax exploitation, the share of taxes in the earnings of the broad strata of the population is constantly increasing. At present, according to foreign economists, it reaches from 30 to $40 \%$ of income, whereas it did not exceed $20 \%$ before the Second World War. The US magazine "US news and world Report" writes that a person whose working day is 8 hours is 2 hours and 42 minutes long.

Finally, the tax burden of inflation increases in connection with the forced overpayments of workers under income taxation. Especially often this happens when paying workers and employees. The emergence of such overpayments is due to the fact that the tax benefits and discounts to which the payer is entitled take time to process them. The family first pays the full amount of the tax, and then all tax benefits and discounts are returned to it. Under the conditions of continuous depreciation of money, the workers receive back sums, the real value of which has fallen markedly, and therefore the tax burden for such families increases. In 1974 there were 126.6 million cases of overpayments to the federal budget of the United States of income and other direct taxes totaling \$28 billion against 52 million cases and 11.4 billion dollars in 1968 (Annual Report 1974, 1975).

As a result of the growth of the tax burden, the severity of which is constantly increasing under the influence of the inflation process, more and more financial resources of the market-developed countries are formed from the revenues from individuals whose professionals account for about $60 \%$ of all direct taxes. Thus, the income of individuals is constantly under the threat of taxes and inflation. Actively working individuals will not save the growth of the non-taxable minimum, the increase in family, personal discounts, or even some reduction in tax rates in certain years.

In developed markets, attention to monetary economics and the government is riveted on the issue of taxes and inflation. For example, if the early postwar years were characterized by low rates of inflation (2-5\% per year), this was considered as a means of stimulating the economy. Higher prices for goods and services should contribute to the development of production, growth of household income and tax revenues. "A small inflation, according to experts, brings at least some benefit" (American Economic Review, 1958).

However, the increase in the rate of inflation, especially in the 60-70s, when the price index in developed countries rises annually by $8-25 \%$, causes concern in business circles.

The sharp depreciation of paper money has an adverse effect on the country's economy, and the general imbalance and disproportion of development are increasing. The rising cost of living and the constant threat of price increases lead to an aggravation of economic contradictions. For the government, inflation undermines the real value of tax revenue. In such conditions, Western science and the government develops anti-inflation programs. To regulate the inflationary process, various methods are recommended, including tax methods. American economists G.Breik and D.Pechman argue that the state "uses taxation in order to stabilize prices, high employment, and satisfactory economic growth." They are echoed by R.Masgrain (USA), considering taxes to be an effective means of combating inflation generated by excessive aggregate demand.

According to the English economist B. Wootton, taxes are a method of controlling "any inflationary growth in personal purchasing power" (Wootton B., 1974). At the same position is $P$. Curwen (Great Britain). He argues that tax measures (direct and indirect taxes, customs duties) have a greater impact on the inflation process (Curwen P., 1976). The views of bourgeois economists on the tax regulation of inflation are the basis of the state policy of most capitalist countries.

In the United States, where direct taxation prevails in the federal tax system, in the fight against inflation, corporate income tax is used to regulate income tax. In order to stimulate economic growth and curb inflation, the US government has repeatedly used tax regulation in conjunction with other measures (in 1964, 1969, 1971 and 1975-1977). In order to expand consumer and investment demand, it reduces personal income tax and corporate income tax. However, the benefits of this are primarily large business. For the masses, the tax burden is not only not decreasing, but, as has been shown, it is increasing, since simultaneously with the reduction of income tax, other taxes are expected to be raised, primarily social security contributions, state and local taxes.

According to historical materials, as early as January 1978 in a special tax message to Congress, US President J. Carter proposed to reduce income tax and corporate income tax in order to invigorate the economy and weaken protracted inflation (Economist, 1976). "According to most calculations, net tax cuts amounted to $\$ 24.5$ billion, it only slightly covered the impact of higher taxes on social insurance, inflation and other factors that reduce purchasing power" (Newsweek, 1978). This was confirmed by the growth of social insurance contributions in the federal budget revenues. If in 1976 it was $28.4 \%$, then in 1979 . It was supposed to bring it to $30.4 \%$. 
In France, indirect taxes and especially value added tax were used as anti-inflationary means. The government of that period (R. Barr) adopted (September 22, 1976) an anti-inflation program, in accordance with which value-added rates were lowered while simultaneously holding back nominal wage growth of no more than $6.5 \%$. Under the influence of inflation, the structure of the tax system (where the decisive role belonged to indirect taxes) gradually began to change in the direction of direct taxation. So, in 1958, indirect taxes if they accounted for about $68 \%$ of all tax revenues of the state budget, and in 1978 this share decreased to $62 \%$. At the same time, there was an increase in the share of income tax (from $14.5 \%$ to $19.8 \%$ over the same years) (Figaro, 1977). Germany also adopted a "anti-inflation stabilization program," in which taxes are given a significant place.

\section{Conclusion}

Reducing taxation, mainly corporate enterprises, the government hoped in this way to stimulate investment demand and promote the growth of production. However, undertaken tax and other methods of regulating inflation have low efficiency. As acknowledged by the press, the "program to combat inflation is so toothless that no one takes it seriously" (New York Times, 1978).

Certainly, government regulation exacerbates old and contributes to the emergence of new contradictions. The economic crisis of 1974-1975. showed the inability of monetary and fiscal leverage to simultaneously deal with the economic crisis, inflation and budget deficits. Life has reaffirmed that in order to suppress inflation, production needs to be regulated.

\section{References}

Toshmatov Sh.A. (2008) The Role of Taxes in Enterprise Development. Monographs. - Tashkent: Science and Technology, p. 204.

Toshmurodova B.E. (2002) The mechanism of taxation management through taxation. - Tashkent: New Age Generation,p. 128.

Malikov T.S, Haydarov N.X. (2007) State budget. Educational manual. - Tashkent: Economy and Finance, p. 21.

Olimjonov O.O. (1999) Financial Management. - Tashkent: Academy, p. 254.
Juraev A.S. Effective ways of formation of state budget revenues. - Tashkent: Fan, 2004. - p. 224.

Gadoev E.F., Kurbonov H.A. (2005) Finance. - T: Creative Union of Writers of Uzbekistan, p. 189.

Zaynalov D.R.(2010)The main approaches to the analysis of the tax and its relationship with the socio-economic processes // Sayapin Readings. pp. 53-68.

Ahrorov Z.O. (2011)Problems of tax regulation of enterprises in a dynamically developing economy. // Development of the banking systems of the world in the conditions of globalization of financial markets: materials of the XII International Scientific and Practical Conference Cherkasy Institute of Banking \& Finance "University of Banking". Cherkasy, 2018. - P.84-87

Zaynalov D.R. (2015) Strengthening the role of existing mechanisms to combat inflation. Institutional development of socio-economic systems: the national economy in the global environment: a collection of scientific works on the materials of the VII International scientific and practical conference. - Poltava: PUT, pp. 90-92.

Report of the Commissioners of Her Majesty's Inland Revenue. 117 Report. L HMSO. December. 1970, p.60/ Economist 15 IV 1978, pp.92,97

S.P. Sarris. (1970) An Improved System of Capitalism and Taxation. N.Y. Privately published p.32

U.S. News and World Report 30 January 1978, p.78

Dandelablait. Dusseldorf. 18 VIII. 1976

Curwen, P. (1976): Inflation, Macmillan Press LTD, London, p.12

U.S.News and World Report. T.IV. 1975,p.28, ibid 7.II.1977,p.62-63

Significant Features of Fiscal Federalism 1976-1977, Wash, 1977,p.97

Economic Notes. May 1972,p.7

Bulletin of foreign commercial information, No. 15, 4 II. 1978 c. 2

Lundberg F. The rich and the super-rich. - New York : Bantam Books, 1969, p.625-626.

Statistical Abstract of the U.S. 1976, Wash. 1976,p.239

Lewis P. Inflation and low incomes. - Fabian Society, 1975, p. II

Hansard. 20 II 1975

Annual Report 1974. Commissioners of Inland Revenue, 1975. Wash., p.9-10; 1969, p.12

American Economic Review, 1958, p.697

Wootton B. Income Policy: An Inquest and a Proposal. London, 1974,p.89

Economist. London, 28 I 1978, p.41

Newsweek. January 30 1978, p.35

Figaro. 4 Janvier 1977, p.1; Le Monde. 24 IX 1977, p.26

New York Times. 13 III 1978 